\title{
Environmental Informatics and Soft Computing Paradigm: Processing of Cocos Nucifera Shell Derived Activated Carbon for Treatment of Distillery Spent Wash-A Solution to Environmental Issue
}

\author{
N. B. Raut, ${ }^{1}$ Dinesh Kumar Saini, ${ }^{2}$ and G. B. Shinde ${ }^{3}$ \\ ${ }^{1}$ Faculty of Engineering, Sohar University, Oman \\ ${ }^{2}$ Faculty of Information Technology, Sohar University, Oman \\ ${ }^{3}$ Department of Chemical Engineering, SVIT, Nashik, Maharashtra, India \\ Correspondence should be addressed to Dinesh Kumar Saini; dinesh@soharuni.edu.om
}

Received 31 December 2013; Accepted 26 June 2014; Published 11 November 2014

Academic Editor: Huu Hao Ngo

Copyright (C) 2014 N. B. Raut et al. This is an open access article distributed under the Creative Commons Attribution License, which permits unrestricted use, distribution, and reproduction in any medium, provided the original work is properly cited.

Soft computing techniques are very much needed to design the environmental related systems these days. Soft computing (SC) is a set of computational methods that attempt to determine satisfactory approximate solutions to find a model for real-world problems. Techniques such as artificial neural networks, fuzzy logic, and genetic algorithms can be used in solving complex environmental problems. Self-organizing feature map (SOFM) model is proposed in monitoring and collecting of the data that are real time and static datasets acquired through pollution monitoring sensors and stations in the distilleries. In the environmental monitoring systems the ultimate requirement is to establish controls for the sensor based data acquisition systems and needs interactive and dynamic reporting services. SOFM techniques are used for data analysis and processing. The processed data is used for control system which even feeds to the treatment systems. Cocos nucifera activated carbon commonly known as coconut shell activated carbon (CSC) was utilized for the treatment of distillery spent wash. Batch and column studies were done to investigate the kinetics and effect of operating parameter on the rate of adsorption. Since the quantum of spent water generated from the sugar industry allied distillery units is huge, this low cost adsorbent is found to be an attractive economic option. Equilibrium adsorption date was generated to plot Langmuir and Tempkin adsorption isotherm. The investigation reveals that though with lower adsorption capacities CSC seems to be technically feasible solution for treating sugar distillery spent. Efforts are made in this paper to build informatics for derived activated carbon for solving the problem of treatment of distillery spent wash. Capsule. Coconut shell derived activated carbon was synthesized, characterized, and successfully employed as a low cost adsorbent for treatment of distillery spent wash.

\section{Introduction}

The wastewater coming from distillery generally known as spent wash is dark brown in color, carries high organic load, and causes severe fouling of the atmosphere. Waste water discharged by distillery from sugarcane molasses poses problems of disposal to acceptable standards due to their high BOD, COD, and color. About 12-15 liters of spent wash is produced per liter of alcohol produced. After fermentation of molasses, alcohol is separated by distillation and the residual liquor is discharged as spent wash. The effluent as such discharged from the plant is hot, dark brown colored, acidic and possesses objectionable odor. The biological oxygen demand (BOD) value are extremely [1] high like the values of suspended solids, dissolved solid, chlorides, sulphates, and nitrogen which are also too high. The potassium content of the effluent is used for irrigation. Though the distillery effluents do not contain any toxic substances, these create toxic wastes resulting in massive fish kills, production of fouls, odors, and decolorisation of streams. The distillery effluent is generally disposed off in open ponds or lagoons. Due to this, seepage and ground water pollution occurs. It 
is a serious threat to soil and water quality because of the melanoid coloring compounds present in the effluent. Also the obnoxiuos odor of the spent wash which spreads a few kilometers can cause serious health concerns.

This massive quantity, approximately 40 billion liters of effluent, from the distilleries are associated with very high organic load with BOD and COD levels in the range of 35,000 to 60,000 and 60,000 to $1,20,000 \mathrm{mg} /$ liter respectively. In India the population equivalent of distillery waste to organic pollution is approximately seven times more than the entire population of India [2]. Environmental regulation in force in India requires that the effluent stress to have $\mathrm{BOD}$ less that $100 \mathrm{mg} /$ liter for discharge on land and less that $30 \mathrm{mg} / \mathrm{liter}$ for discharge into inland surface waters. These stipulations necessitate further treatment of effluent [3].

A number of conventional treatment technologies have been considered for treatment of wastewater contaminated with organic substances. Among them, adsorption process is found to be the most effective method. Adsorption as a wastewater treatment process has aroused considerable interest during recent years. Commercial activated carbon is regarded as the most effective material for controlling the organic load [4]. However due to its high cost and about 10$15 \%$ loss during regeneration, unconventional adsorbents like coconut shells, fly ash, peat, lignite, bagasse pith, wood, saw dust, and so forth have attracted the attention of several investigations and adsorption characteristics have been widely investigated for the removal of refractory materials $[5,6]$ for varying degree of success. Activated charcoal is charcoal made from wood, coconut shell, or bone, which has been treated with oxygen to remove all the impurities sticking to its surface inside the pores. Activated charcoal, for example, can have a total surface area of up to 2000 square meters per gram [7]. There is lots of surface to hold molecules, which remain in place by Vander Waals forces (physisorption). The bigger its surface area, the more molecules it can trap on its surface [8].

It is felt that the shells can be used for producing an adsorbent for treating distillery spent wash from sugar industry using adsorption process [9].

In most of the coastal cities and towns across the globe, Cocos nucifera commonly known as coconut trees is plentiful and the green empty coconuts finds their way in the cities refuse. In some places the green nuts are dried and the fibers are removed for various purpose like rope making, floor mats or rubberized coir mattresses, and so forth; however, the shells are not much used other than for use as fuel. Coconut shells are made up of "stone cells" and are hard, porous, impregnated with lignins and tannin and a little oil.

Steam activation and chemical activation are the two commonly used processes for the manufacture of activated carbon. However coconut shell based activated carbon units are adopting the steam activation process to produce good quality activated carbon [10].

Lowering of $\mathrm{pH}$ value of the stream, increase in organic load, depletion of oxygen content, destruction of aquatic life, and bad smell are some of the major pollution problems due to distillery wastewater. One of the main advantages of COD [4] reduction by using coconut shell ash over the other
TABLE 1: Required containers, preservation techniques, and holding times for samples.

\begin{tabular}{|c|c|c|c|}
\hline $\begin{array}{l}\text { Maximum } \\
\text { holding time }\end{array}$ & Preservative & Container & Parameter \\
\hline 14 days & $\mathrm{Cool} 4^{\circ} \mathrm{C}$ & P.G. & Acidity \\
\hline 14 days & $\mathrm{Cool} 4^{\circ} \mathrm{C}$ & P.G. & Alkalinity \\
\hline 48 hours & $\operatorname{Cool} 4^{\circ} \mathrm{C}$ & P.G. & BOD \\
\hline 28 days & $\begin{array}{c}\mathrm{Cool} 4^{\circ} \mathrm{C}, \\
\mathrm{H}_{2} \mathrm{SO}_{4} \text { to } \mathrm{pH}<2\end{array}$ & P.G. & COD \\
\hline 28 days & $\begin{array}{c}\mathrm{Cool} 4^{\circ} \mathrm{C} \\
\mathrm{H}_{2} \mathrm{SO}_{4} \text { to } \mathrm{pH}<2\end{array}$ & G. & Phenols \\
\hline 0 hours & None required & P.G. & $\mathrm{pH}$ \\
\hline 0 hours & None required & G. & DO \\
\hline 48 hours & $\mathrm{Cool} 4^{\circ} \mathrm{C}$ & P.G. & Nitrate \\
\hline 7 days & $\mathrm{Cool} 4^{\circ} \mathrm{C}$ & P.G. & Residue volatile \\
\hline 7 days & $\mathrm{Cool} 4^{\circ} \mathrm{C}$ & P.G. & TSS \\
\hline
\end{tabular}

chemical treatment methods is that it is available as a waste material in abundance and easy availability makes it a strong choice in the investigation of economic way of COD removal [11].

\section{Material and Methods}

2.1. Sample Collection and Pretreatment. The distillery spent wash sample was taken from Niphad Sahakari Sakhar Karkhana, Niphad, Dist. Nashik, and Maharashtra India. Once a sample is taken, the constituents of the sample should be maintained in the same condition, as when collected. When it is not possible to analyze collected samples immediately, samples should be preserved properly in such a way that the biological activity (microbial respiration), chemical activity (precipitation or $\mathrm{pH}$ change), and physical activity are the minimum. Methods of preservation [12] include cooling, $\mathrm{pH}$ control, and chemical addition as shown in Table 1. Freezing is usually not recommended. The length of time in which a constituent in waste water will remain stable is related to the character of the constituent and preservation method used.

2.2. Production of Activated Carbon. The coconut shells derived from various waste sources were cleanly shaved to remove all the fibers on its surface. Cleaned shells were cut into $3 \mathrm{~mm}$ to $8 \mathrm{~mm}$ pieces. These pieces were washed with distilled water to remove surface dust and dried in sunlight for two to three days.

The cleaned and dried coconut shells were then broken into small pieces to allow insertion into a muffle furnace $\{\mathrm{KW}=0.3, \mathrm{AMP}=13, \mathrm{TYPE}=\mathrm{MFRA}, \mathrm{PHASE}=$ Single $\}$ and subjected to destructive distillation in the absence of air. The temperature of the furnace was maintained at $400^{\circ} \mathrm{C}$ for three hours to avoid reactions with atmospheric oxygen, thereby preventing formation of ash. This resulted in the formation of black carbonized matter. The carbonized matter was washed [13] with distilled water and dried at $100^{\circ} \mathrm{C}$. These 
TABLE 2: Characteristics of adsorbents.

\begin{tabular}{lccc}
\hline Sr. no. & Characteristics & CSC & CAC \\
\hline 1 & Moisture, \% & 16.26 & 6.37 \\
2 & Ash content, \% & 0.33 & 4.51 \\
3 & Bulk density, g/cc & 0.67 & 0.57 \\
4 & Matter soluble in water, \% & 1.32 & 1.31 \\
5 & Matter soluble in acid, \% & 2.25 & 1.39 \\
6 & $\mathrm{pH}$ & 2.40 & 8.50 \\
7 & Decolorizing power, $\mathrm{mg} / \mathrm{g}$ & 39 & 78 \\
8 & Surface area, $\mathrm{m}^{2} / \mathrm{g}$ & 1.69 & 337 \\
\hline
\end{tabular}

pieces were broken down into fine powder with the help of grinder and size separation which is done by screening using standard sieves [4]. Commercial activated carbon (CAC) was procured from M/s Dayo Scientific Sales, Nashik Road, Nashik, Maharashtra, India. The typical properties of CSC and CAC are summarized in Table 2.

2.3. Batch Adsorption Tests. To study the effect of important parameters like initial $\mathrm{pH}$, adsorbent dose (gm), contact time $(t)$, initial concentration $\left(C_{o}\right)$, adsorbent particle size, and agitation speed on the adsorptive removal of COD by CSC and CAC, batch experiments were conducted at $30^{\circ} \mathrm{C}$. For each experimental run, $50 \mathrm{~mL}$ of distillery spent wash solution of known $C_{o}, \mathrm{pH}$, and a known amount of adsorbent dose was taken in a $100 \mathrm{~mL}$ stoppered conical flask. This mixture was agitated in a temperature controlled shaking water bath at a constant speed of $90 \mathrm{rpm}$ at $30^{\circ} \mathrm{C}$. Samples were withdrawn at appropriate time intervals and analyzed for COD. The effect of $\mathrm{pH}$ on COD removal was studied over a $\mathrm{pH}$ range of 3 to 11. $\mathrm{pH}$ was adjusted by the addition of dilute aqueous solutions of $\mathrm{NaOH}(0.10 \mathrm{M})$ or $\mathrm{HCl}$. For the optimum amount of adsorbent dose (gm), a $50 \mathrm{~mL}$ of distillery spent wash solution was contacted with different amounts of CSC and CAC till equilibrium was attained.

The kinetics of adsorption was determined by analyzing adsorptive $[14,15]$ uptake of COD from the distillery spent wash at different time intervals. For adsorption isotherms, distillery spent wash samples of different concentrations were agitated with the known amount of adsorbent till the equilibrium was achieved. The samples were then analyzed for COD removal. The effect of speed of agitation was studied by agitating the samples at different known speed of agitation and analyzing agitated samples for COD.

2.4. Column Adsorption Tests. Columns are mounted vertically one above the other. It is often good practice to operate columns in upflow as this reduces the opportunity for channeling. It is also preferred where suspended solids create a high-pressure drop. For downflow or percolation system an influent line should be installed at the top of column with effluent line at bottom. To develop reasonably good data from scaleup to full plant design, it is important to have operation of the pilot column system as near as possible to the anticipated conditions. The most critical factors, flow rate and feed impurity concentration, must be constant for the entire test run. The adsorbent bed should be at least $60 \mathrm{~cm}$ deep with a $4 \mathrm{~cm}$ internal diameter. A smaller column is not recommended as the wall effect becomes significant. The adsorbent bed can be supported by glass wool, wire cloth, and so forth. Columns and fixtures can be constructed from glass, plastic, reinforced fiberglass, or metal. Borosilicate glass is commonly used. It is essential that all columns used in the pilot system have at least the same diameter [16].

A bed volume is the volume occupied by the adsorbent including adsorbent volume and void volume. The quantity of effluent is expressed in the number of adsorbent volumes passing through the column per hour. As the flow rate and quantity of liquor are the most important controllable variables in developing design data, a feed pump suitable for accurate and continuous flow is required. Depending on the size of the pilot column system, the use of peristaltic, diaphragm, piston type, and centrifugal pumps is recommended if the effluent is viscous.

When loading the column care should be taken to avoid entrapping air in the adsorbent bed. Entrapped air can cause channeling during operation preventing complete contact of the process effluent with the adsorbent. In small columns entrapped air can be avoided by pouring out the adsorbent in the boiling water just before loading of most of the excess water can be poured off, along with most of the adsorbent particles. Before starting the test the complete system should be checked by running on water for several hours. After setting the appropriate flow rate, the effluent to be treated can be fed to the columns and this will displace the water. Samples of effluent after each column should be taken at regular intervals of time. When the effluent from the parallel columns or last column in series exceeds the purity requirement, the test should be stopped [17].

\section{Results and Discussion}

3.1. Distillery Spent. Characteristics of spent wash vary widely depending upon the quality of raw material, process technology, energy conservation, and effluent treatment strategies. The typical composition of spent wash from Niphad Sahakari Sakhar Karkhana, Niphad, Tal Niphad, Dist. Nashik, is given in Table 3. India, which is one of the largest producers of sugar, produces the poorest quality of molasses. Indian molasses contain the lowest amount of sugars and the highest amount of impurities and nonfermentable sugars. This impure molasses typically contains the higher amount of mineral matter, calcium oxide, and potash which is further degraded by poor storage facilities at the sugar factories, before it is lifted by the distilleries. During the short storage time at the sugar mills, dust and other extraneous materials of unknown origin contaminate it. Most of the components found in molasses are from the sugarcane and find their way to molasses because of the rigorous extraction [18] procedures to molasses because of the intensive extraction process. In Brazil, for example, which is also a large sugar producer, the processes of sugar extraction and recovery are mild and, as consequence, the composition of molasses is superior. Similarly, in other sugarcane producing countries, no attempt is made to recover maximum quantity of sugar 
TABLE 3: Typical composition of distillery spent wash. From Niphad Sahakari Sakhar Karkhana, Niphad, Dist, Nashik.

\begin{tabular}{lcc}
\hline Sr. no. & Parameter & Spent wash analysis \\
\hline 1 & $\mathrm{pH}$ & 7.87 \\
2 & Suspended solids & $56,891 \mathrm{mg} / \mathrm{lit}$ \\
3 & Total dissolved solids & $2,41,066.6 \mathrm{mg} / \mathrm{lit}$ \\
4 & B.O.D. at $27^{\circ} \mathrm{C}$ for 3 days & $24,000 \mathrm{mg} / \mathrm{lit}$ \\
5 & C.O.D. & $39,840 \mathrm{mg} / \mathrm{lit}$ \\
6 & Oil and grease & $23.0 \mathrm{mg} / \mathrm{lit}$ \\
7 & Sulphate & $4,000 \mathrm{mg} / \mathrm{lit}$ \\
8 & Potassium & $1,3000 \mathrm{mg} / \mathrm{lit}$ \\
9 & Chloride & $1,00,000 \mathrm{mg} / \mathrm{lit}$ \\
10 & Sodium & $1,200 \mathrm{mg} / \mathrm{lit}$ \\
11 & Calcium & $2,600 \mathrm{mg} / \mathrm{lit}$ \\
12 & Magnesium & $2,700 \mathrm{mg} / \mathrm{lit}$ \\
13 & Iron & $61 \mathrm{mg} / \mathrm{lit}$ \\
14 & Total nitrogen & $1,350 \mathrm{mg} / \mathrm{lit}$ \\
15 & Colour & Dark brown \\
16 & Odor & Smell of burnt sugar \\
17 & Temperature & $90-95^{\circ} \mathrm{C}$ \\
\hline
\end{tabular}

from the cane. Lately sugar factories have begun to use certain specific chemicals such as biocide, flocculating agents, color, and viscosity reducing agents which all ultimately make their way into molasses, making it more difficult to be degraded by microorganism.

The composition of the effluent is a reflection of the composition of the molasses. A bad molasses produces a bad effluent. Thus, the poor quality of the cane molasses produced by the sugar mills is responsible for the complex character of the distillery effluent. The composition of the molasses from different sugar mills used in different distilleries in India also varies, due to different processes of sugar manufacture.

In matter of characteristics, effluent is normally a diluted replica of the molasses pressed in the production of alcohol. If molasses differ in composition, as a natural corollary it would yield an effluent, which would also differ in composition and as a consequence the extent of BOD reduction during primary treatment of the effluent would also differ [19]. This makes the situation more complicated as no single technology could produce similar results in all types of effluents and reduce the BOD to an identical level. The effluents of Indian molasses based distilleries have the highest BOD/COD and contain a high percentage of inorganic and organic dissolved matter, compared to the effluents of other countries. The highly dissolved organic matter, which cannot be utilized by yeast and which ultimately finds its way into the effluents, is primarily responsible for escalating the high biological oxygen demand (BOD). In addition, during the fermentation of molasses by yeast, the yeast cells multiply and also produce other organic compounds such as organic acids and so forth, in addition to alcohol. The yeast cells and organic acids also form a part of the effluent and contribute to the BOD. A molasses rich in salts and other minerals allows the yeast to produce a higher amount of organic components, some

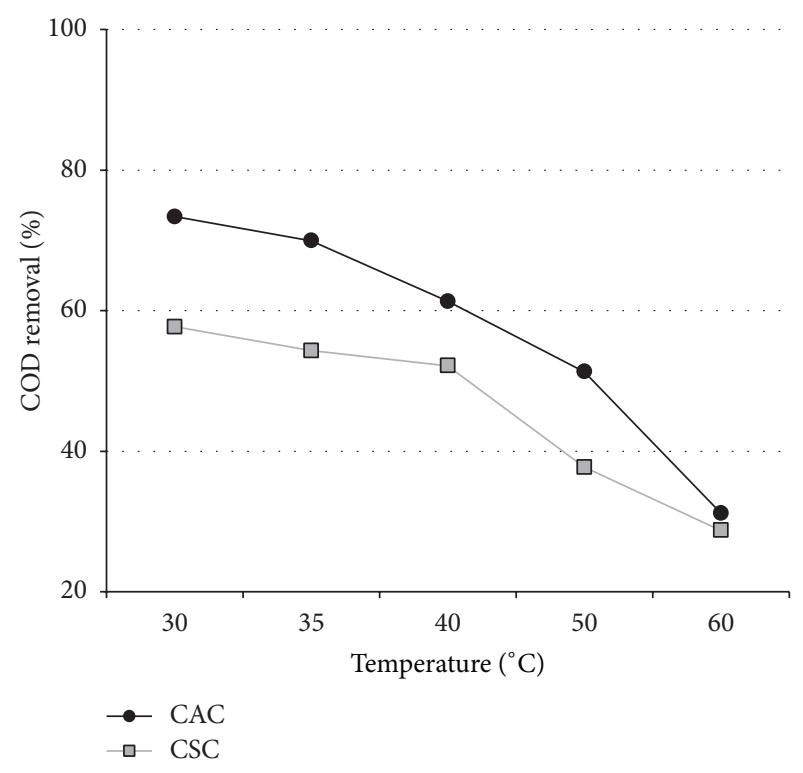

Figure 1: Effect of temperature on COD removal, $C_{o}=13120 \mathrm{mg} / \mathrm{L}$, time $=1 \mathrm{hr}$, and adsorbent dose $=2 \mathrm{gms}$.

of which may not be easily degraded. In India both the composition of molasses as well as the effluent is complex primarily because of the sugar recovery process. In other countries, the BOD of the effluent is low and is therefore amenable to easy degradation. The Indian cane molasses effluent contains a very high BOD and its treatment needs special technology [14].

\subsection{Adsorption Test}

3.2.1. Effect of Temperature on COD Removal. Usually, the adsorption reactions are exothermic; high temperature or slow adsorption would seem to inhibit, but this is not usually found to be a factor in most systems. Adsorption rate is limited by diffusion; variable that influences diffusion has significant effect on adsorption rate. Higher temperatures may obstruct adsorption sight, but they significantly speed up the pace of diffusion, offending any negative temperature effect. The temperature dependence of adsorption process is of a very complex nature. Thermodynamic parameter like heat of adsorption and the energy of activation plays an important role in predicting the adsorption behavior and both are strongly temperature dependent. Heat of adsorption influences the equilibrium absorption capacity and also indicates that the nature of interaction taking place between the adsorbate and adsorbent is dependent of the energy of activation.

The decrease in adsorption with the rise in temperature may be due to weakening of adsorptive forces between the active sites of the adsorbent and adsorbate species and also between the adjacent molecules of the adsorbed phase [14, 20]. Figure 1 shows the result of variation in adsorption rate with temperature. It has been generally observed that with the increase in temperature the percent removal of organic matter 


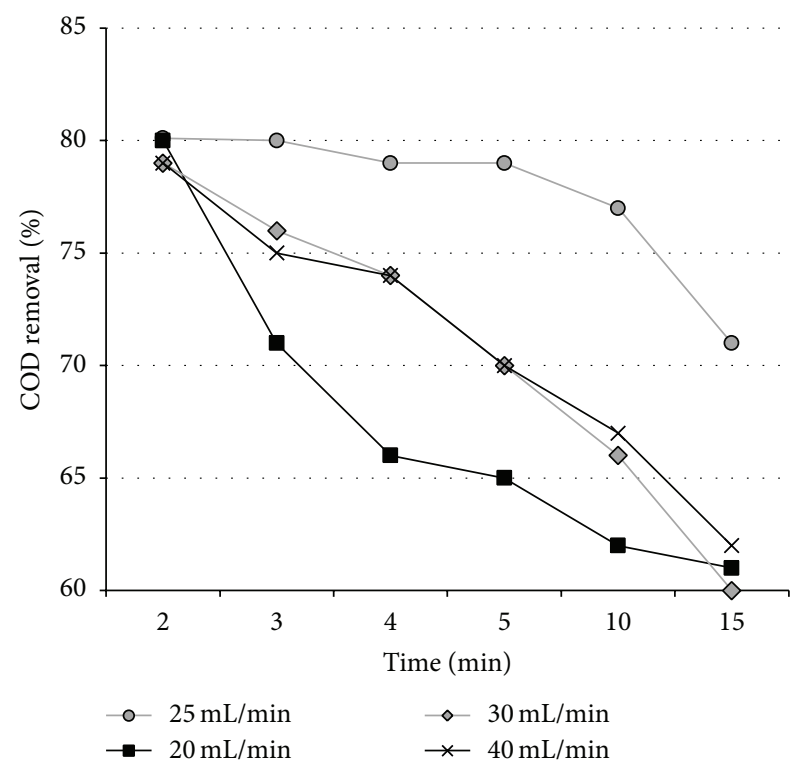

Figure 2: Effect of flow rate on COD removal (CSC), $C_{o}=13120$ $\mathrm{mg} / \mathrm{L}$, bed depth $=45 \mathrm{Cm}$, and temperature $=30^{\circ} \mathrm{C}$.

(COD) due to the adsorption decreases which is also evident from our results. The rate of adsorption is optimum within 30 to $45^{\circ} \mathrm{C}$.

It may be observed that the (COD) removal rate for activated carbon is higher and slightly lower for coconut shell ash. But due to the easy availability of coconut shells it is more suitable adsorbent than commercial activated carbon. It may be concluded that, at higher temperature, the decrease in the adsorption could be due to the possible exothermic nature of the adsorption process. In the present study, the optimum (COD) removal was found near at room temperature (25$\left.35^{\circ} \mathrm{C}\right)$.

3.2.2. Effect of Flow Rate on Adsorption. The effect of flow rate on removal of COD is shown in Figures 2 and 3. It may be observed that in general the percentage COD removal decreases with increase in the flow rate. The rate of adsorption decreases with increase in the flow rate due to decrease in the residence time for the contact of adsorbate with adsorbent. The COD reduction was remarkable at a flow rate of $25 \mathrm{~mL} / \mathrm{min}$ dropping gradually but steadily in case of CSC but it dropped sharply with CAC under the same conditions.

3.2.3. Effect of $p H$ on COD Removal. During adsorption both anions and captions have been removed from waste water with adsorbent. Researchers have found that carbon exhibits preferential adsorption for ionic species in an order of preference as $\mathrm{Al}^{+3}>\mathrm{Ca}^{+2}>\mathrm{Li}^{+}>\mathrm{Na}^{+}>\mathrm{K}^{+}$. For anions, the $\mathrm{NO}_{3}$ ion is preferred over the $\mathrm{Cl}^{-}$ion. It is not surprising that $\mathrm{pH}$ plays an important role in the adsorption characteristics of these ions as the low $\mathrm{pH}$ provides large quantities of the preferred $\mathrm{H}^{+}$ion, which may take the space of other ions on potential adsorption sites. Even without

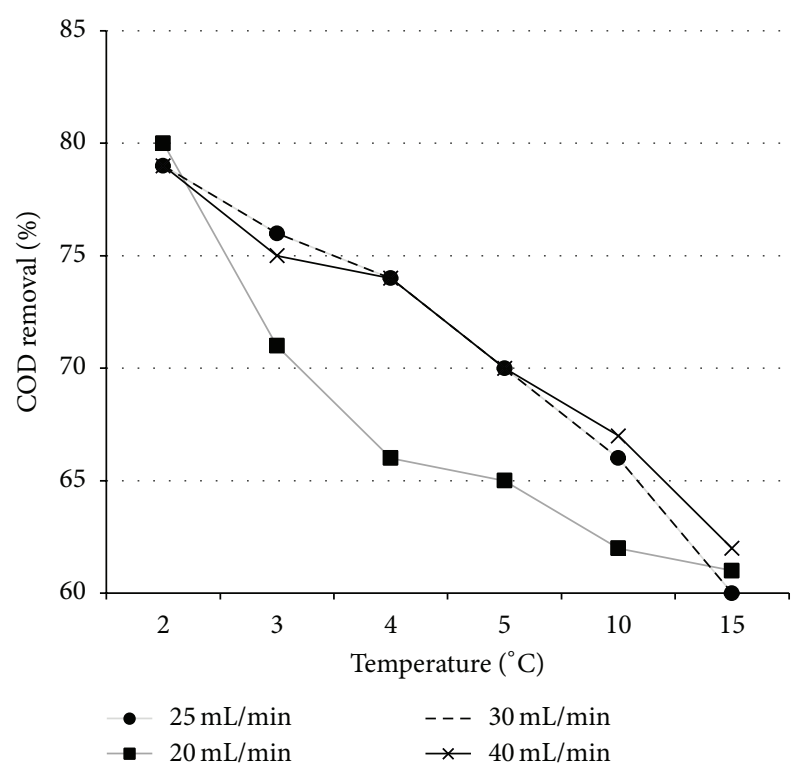

Figure 3: Effect of flow rate on COD removal (CAC), $C_{o}=13120$ $\mathrm{mg} / \mathrm{L}$, bed depth $=45 \mathrm{Cm}$, and temperature $=30^{\circ} \mathrm{C}$.

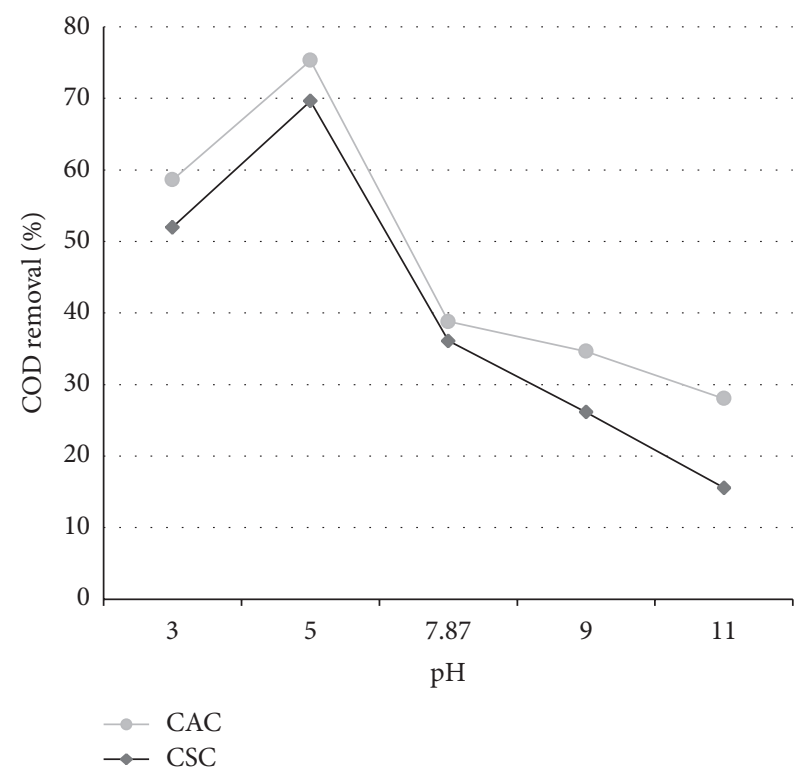

Figure 4: Effect of $\mathrm{pH}$ on COD removal (CAC), $C_{o}=13120 \mathrm{mg} / \mathrm{L}$, agitation time $=1 \mathrm{hr}$., adsorbent dose $=2 \mathrm{gms}$, and temperature $=$ $30^{\circ} \mathrm{C}$.

$\mathrm{pH}$ variations inorganic compounds exhibit a wide range of absorbability on adsorbents. The adsorption by using coconut shell ash and commercial activated carbon was studied at different $\mathrm{pH}$ values from 3 to 11. Figure 4 shows the removal of $\mathrm{COD}$ as a function of $\mathrm{pH}$. Any adsorbate adsorbent system $\mathrm{pH}$ of the system affects the nature of the surface change of the adsorbent, extend of ionization, and the extent and the rate of adsorption. From graph it may be seen that the COD removal increases as $\mathrm{pH}$ increased from 3 to 5 . Thereafter, the removal decreases with further increase in $\mathrm{pH}$. Similar observations 


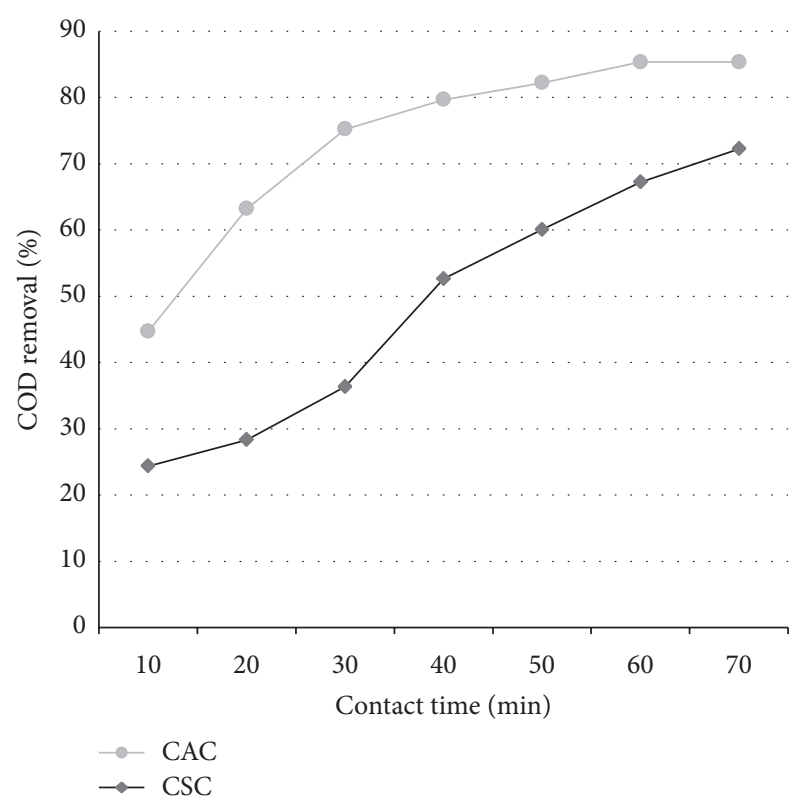

Figure 5: Effect of contact time on COD removal (CAC), $C_{o}=$ $13120 \mathrm{mg} / \mathrm{L}$, adsorbent dose $=2 \mathrm{gms}$, and temperature $=30^{\circ} \mathrm{C}$.

have been reported for COD removal from distillery effluents using activated carbon.

3.2.4. Effect of Adsorbent Dose on COD Removal. The effect of adsorbent dose on removal of COD is shown COD in Figure 5. It may be observed that in general the percentage COD removal increases with increase in the adsorbent dose. From graph it is noted that the rate of decrease of percentage COD removal has been found to be rapid in the beginning, which slows down as the dose increased. The rate of adsorption increases with increase in dosage because of increase in surface area of the adsorbent [21].

3.2.5. Effect of Contact Time on COD Removal. In column adsorption the rate of adsorption goes on decreasing with the passage of time which is shown in Figure 5 because as the time passes the adsorption sites of the adsorbent are utilized for the adsorption of the organic matter and the stage is reached when all the sites are used and the adsorbent is saturated. In batch study it is concluded that the optimum time for adsorption is up to $60-70 \mathrm{~min}$ only. After that the removal rate was very low. Generally, the rate of adsorption increases with time and after some time it remains constant [22] due to equilibrium condition.

3.2.6. Effect of Adsorption on Color Removal. Colorization of distillery effluent has been a cause of major concern and even after the primary treatment and two-stage biological treatment (anaerobic followed by aeration) the color is not destroyed. Adsorption experiments were carried on distillery effluent using coconut shell ash and commercial activated carbon. Color removal of $40-50 \%$ was observed in case of coconut shell ash while in case of activated carbon as

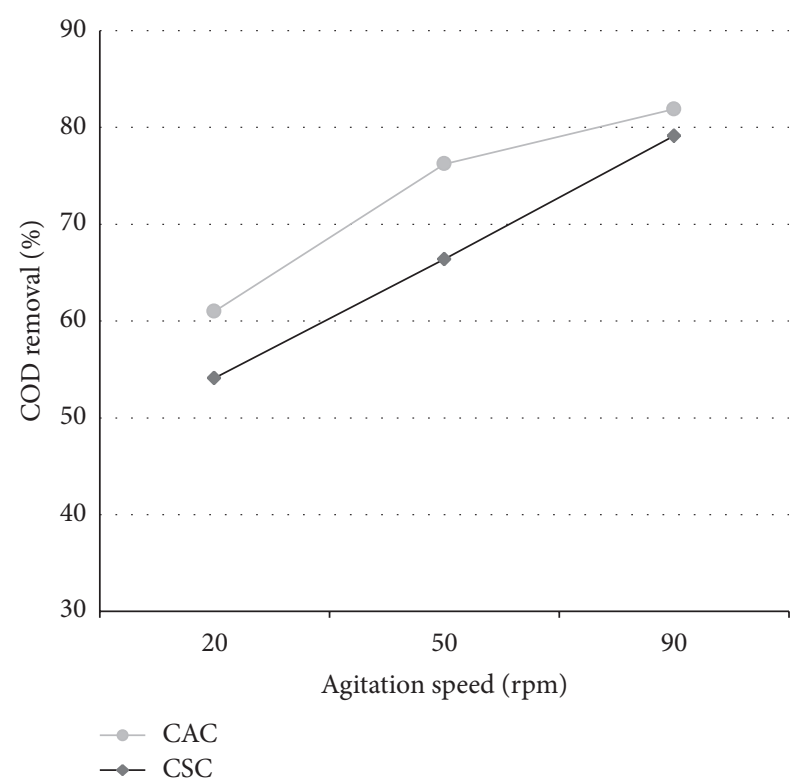

FIGURE 6: Effect of agitation speed on COD removal (CAC), $C_{o}=13120 \mathrm{mg} / \mathrm{L}$, adsorbent dose $=2 \mathrm{gms}$, agitation time $=1 \mathrm{hr}$, temperature $=30^{\circ} \mathrm{C}$, and $V=50 \mathrm{~mL}$.

adsorbent (dose of $20 \mathrm{gm} / \mathrm{L}$ ) color removal of $70-75 \%$ was observed.

From Figure 6, it can be seen that there is an increase in the rate of COD removal with respect to the increase in agitation speed of the mechanical shaker. This is because the resistances to the mass transfer, which is mainly present around the surface of the adsorbents, breaks down with increasing agitation speed [23]; as a result more amount of organic matter penetrates into the adsorbents with ease.

3.2.7. Effect of Concentration on Adsorption. The effect of concentration on adsorption is shown in Figure 7. It can be concluded that from highly concentrated effluent the COD removal quantity is more than dilute. So this indicates that the effluent can be directly used for the treatment without dilution. At low concentration COD removed quantity is low. The COD reduction is optimum at a concentration above $8500 \mathrm{mg} / \mathrm{lit}$ for both CAC and CSC.

3.2.8. Effect of Adsorbent Bed Depth on COD Removal. The effect of adsorbent bed depth on adsorption, that is, COD removal in this case, was studied by packing the adsorption column with different depths of the adsorbent $(20 \mathrm{~cm}, 30 \mathrm{~cm}$, and $45 \mathrm{~cm}$ ). The results are shown in Figure 8. The adsorption increased with increasing the adsorbent bed depth in agreement with the earlier work $[18,20]$. The effect of adsorbent bed depth on COD removal was studied with respect to different flow rates $20 \mathrm{~mL} / \mathrm{min}$., $30 \mathrm{~mL} / \mathrm{min}$., and $45 \mathrm{~mL} / \mathrm{min}$. of the effluent.

3.2.9. Bed Depth Service Time (Bohart Adam's Model). In continuous flow experiments, it is essential to predict the exhaustion rate of adsorbent bed on how long the bed will last 


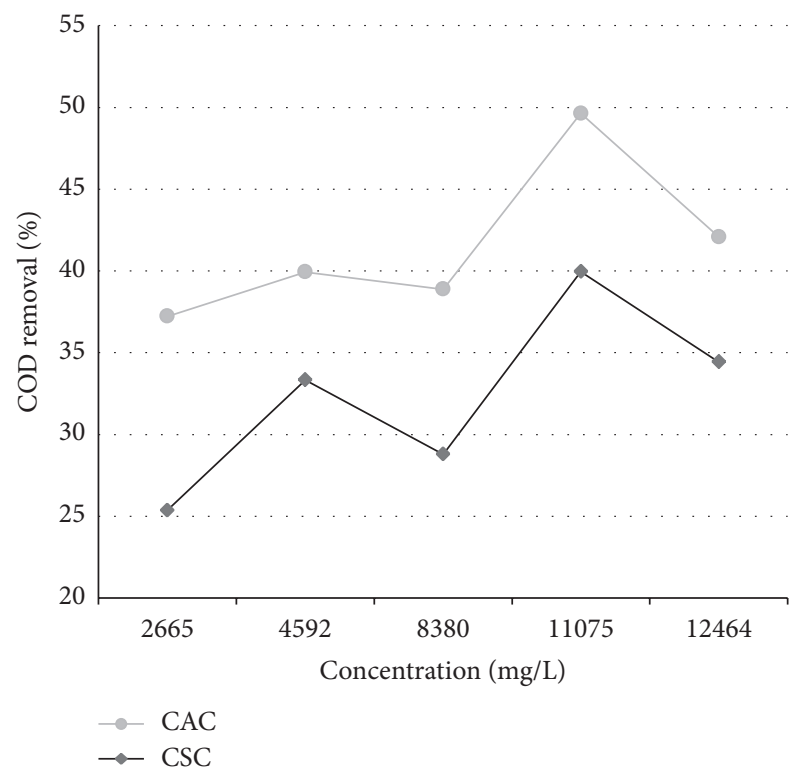

FIGURE 7: Effect of concentration on COD removal, adsorbent dose $=2$ gms.

before regeneration is necessary. In this method the service time of a fixed bed adsorbent, treating a solution of single adsorbate, can be expressed as a function of operational variables as shown by (1).

The straight line plots of breakthrough time versus bed height were obtained as shown in Figure 9 indicating the applicability of Bohart Adam's model:

$$
\begin{gathered}
\ln \left(\frac{C_{0}}{C_{b}}-1\right)=\ln \left(\frac{K N_{o} H}{V}\right)-1-K_{b} C_{0} T_{b}, \\
T_{b}=\left(\frac{N_{0}}{C_{0} V}\right) H-\left(\frac{V}{K_{b} N_{0}}\right) \ln \left(\frac{C_{0}}{C_{b}}-1\right),
\end{gathered}
$$

where $C_{b}=$ breakthrough concentration $\{\mathrm{mg} / \mathrm{L}\}, C_{0}=$ initial concentration $\{\mathrm{mg} / \mathrm{L}\}, H=$ critical bed depth $\{\mathrm{m}\}, V=$ linear flow velocity $\{\mathrm{m} / \mathrm{min}\},. K_{b}=$ rate constant, $T_{b}=$ breakthrough time $\{$ Min. $\}$, and $N_{0}=$ adsorptive capacity $\{\mathrm{mg} / \mathrm{m}\}$.

The breakthrough time is found to increase with increase in the adsorbent bed height. Thus, column test shows the applicability of BDST model [8].

\subsubsection{Effect of Particle Size of Adsorbent on COD Removal.} The effect of using various particle sizes of CSC on COD removal was studied by using CSC adsorbent of three different particle sizes, namely, 425 microns, 610 microns, and 750 microns for the column experiments. The Co was kept constant at $20480 \mathrm{mg} / \mathrm{lit}$. and all the experiments were carried out at natural $\mathrm{pH}$ of 7.87 and temperature $30^{\circ} \mathrm{C}$.

From the results (Figure 10) it is clear that the rate of adsorption increases with decrease in particle size. This is because increase in the surface area with the decreasing particle size of adsorbents and since adsorption process is a surface phenomenon the rate of adsorption increases with decrease in particle size. Thus the smaller the particle size, the

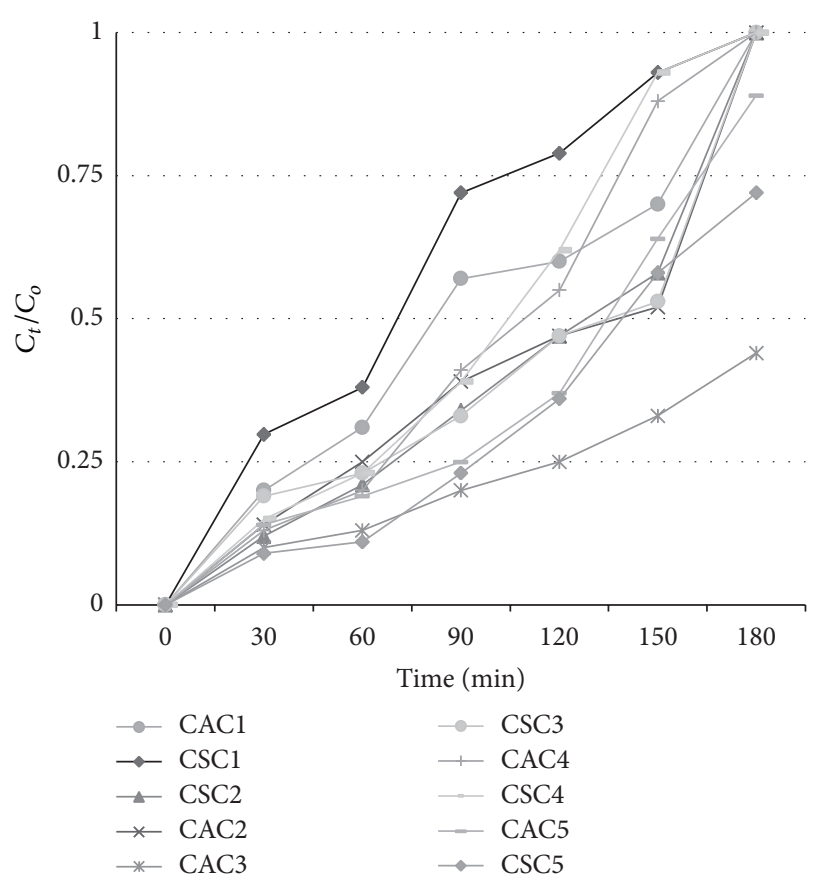

FIGURE 8: Effect of adsorbent bed height on rate of COD removal $C_{o}=13120 \mathrm{mg} / \mathrm{L}$, temperature $=30^{\circ} \mathrm{C} 1=H=20 \mathrm{Cm}$, flow rate $=$ $20 \mathrm{~mL} / \mathrm{min}, 2=H=30 \mathrm{Cm}$, flow rate $=20 \mathrm{~mL} / \mathrm{min}, 3=H=45 \mathrm{Cm}$, flow rate $=20 \mathrm{~mL} / \mathrm{min}, 4=H=20 \mathrm{Cm}$, flow rate $=30 \mathrm{~mL} / \mathrm{min}, 5=$ $H=30 \mathrm{Cm}$, flow rate $=30 \mathrm{~mL} / \mathrm{min}, 6=H=45 \mathrm{Cm}$, and flow rate $=$ $30 \mathrm{~mL} / \mathrm{min}$.

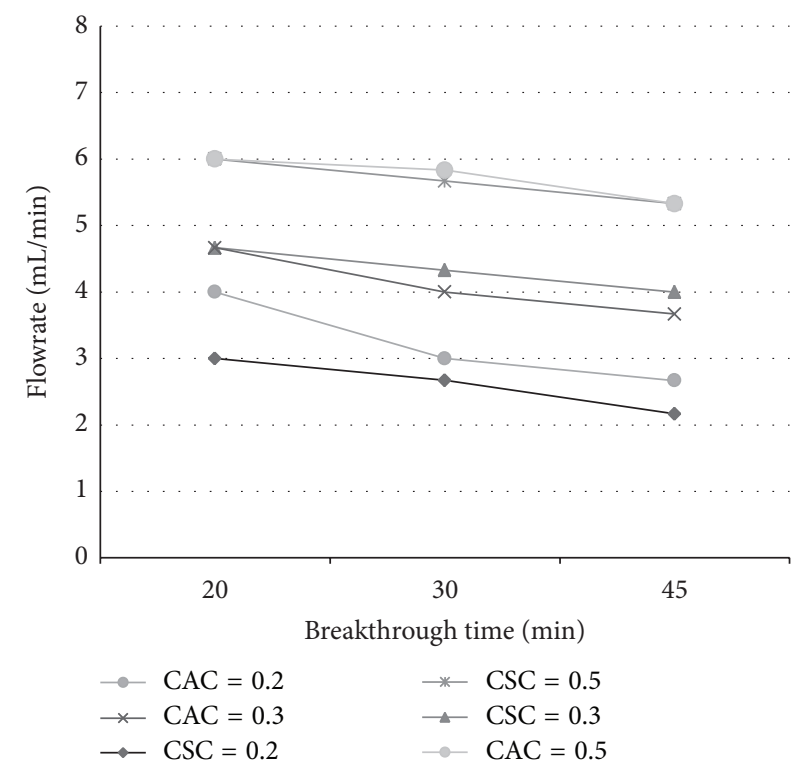

Figure 9: Bohart Adam's model.

greater the interfacial area for adsorption of COD. But with the reduced sizes, there may be other problems like clogging during the operation particularly with continuous operations resulting in high- pressure drops.

3.2.11. Effect of Series Arrangement of CSC and CAC Columns. Figure 11 shows that if the CSC column is arranged in series 


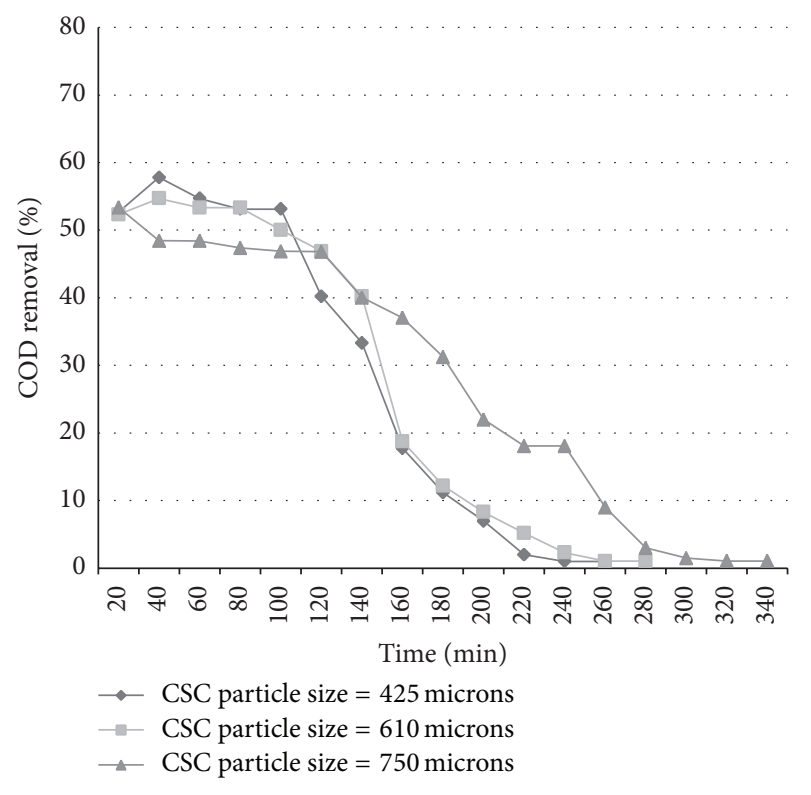

FIgURE 10: Effect of particle size on COD removal (CAC), $C_{o}=$ $20480 \mathrm{mg} / \mathrm{L}, H=12 \mathrm{~cm}$, flow rate $=45 \mathrm{~mL} / \mathrm{min}$.

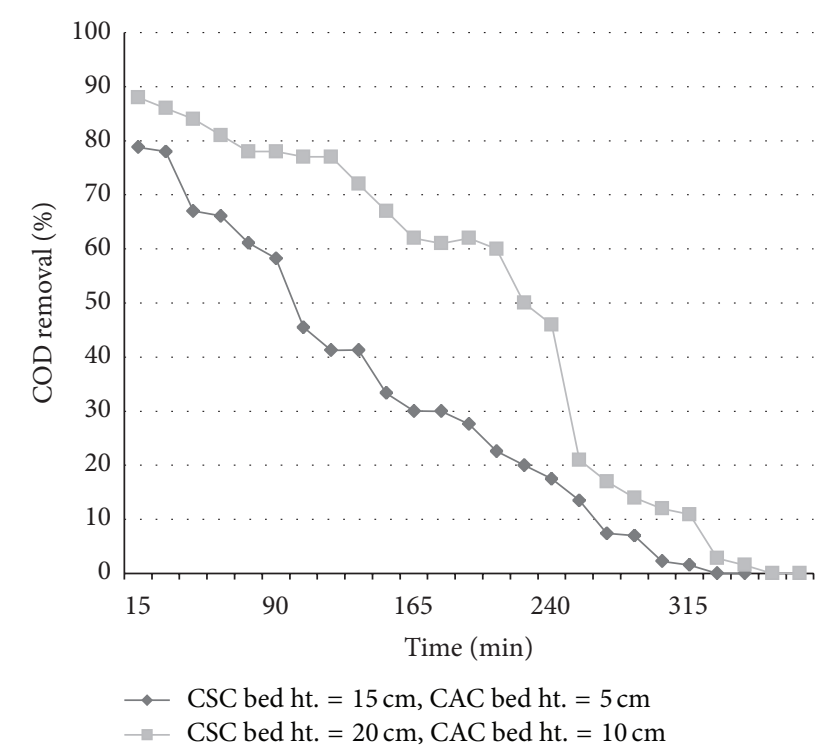

FIGURE 11: Effect of CSC column in series with CAC bed on COD removal, $C_{o}=20480 \mathrm{mg} / \mathrm{L}$.

with CAC column for adsorption operation, the efficiency of carbon utilization is increased. Thus, more quantity of CSC adsorbent and less quantity of CAC adsorbent can be effectively used for treating distillery spent. Though the percentage COD removal using series combination is slightly less than that using the two columns separately but the low cost of CSC makes it an attractive option.

\subsection{Adsorption Isotherms}

3.3.1. Langmuir Adsorption Isotherm. The equilibrium data for removal of COD by using CSC and CAC in the present

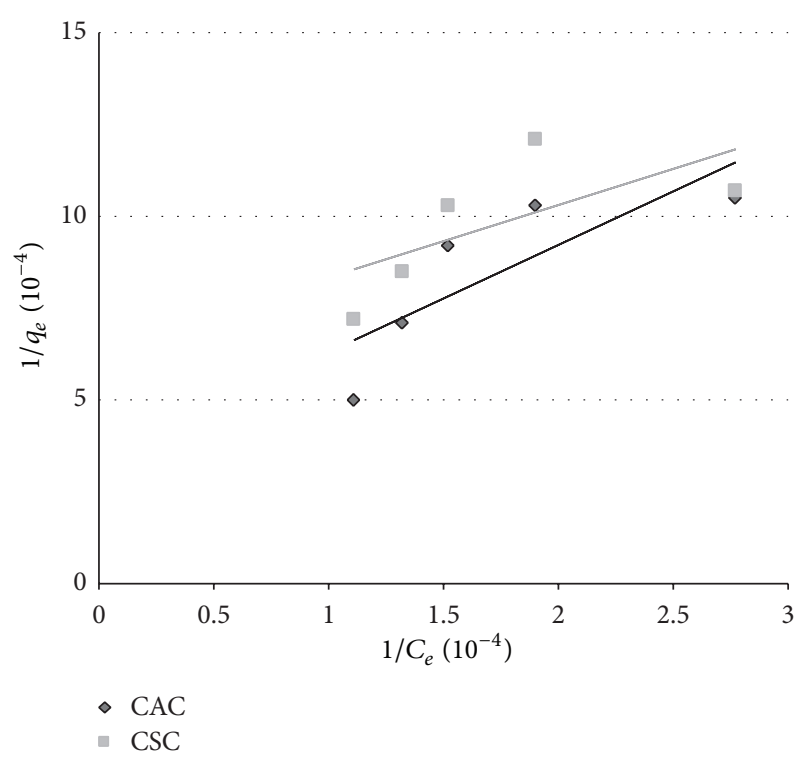

FIGURE 12: Langmuir adsorption isotherm $C_{o}=13120 \mathrm{mg} / \mathrm{L}$.

investigations were analyzed using Langmuir adsorption model. The linear plots of $1 / q_{e}$ versus $1 / C_{e}$ are shown in Figure 12. The values of $\theta$ and $b$ were determined as intercept $=1 / \theta^{0}$ and slope $=1 / \theta^{0} b$. The adsorption data were fitted to the linear form of Langmuir isotherm. The essential characteristics of Langmuir isotherm may be expressed in terms of dimensionless equilibrium parameter $R$ using following equation:

$$
R=\frac{1}{\left(1+b C_{0}\right)}
$$

The values of $R$ lie between "0" and "1" at initial adsorbate concentrations showing favorable adsorption of organic matter on the adsorbent.

$$
\begin{aligned}
& \text { For CSC, } b_{\mathrm{CSC}}=4.9685 \times 10^{-4} R_{\mathrm{CSC}}=0.133 \\
& \text { For CAC, } b_{\mathrm{CSC}}=1.24 \times 10^{-5} R_{\mathrm{CAC}}=0.860
\end{aligned}
$$

3.3.2. Tempkin Adsorption Isotherms. A plot of $q_{e}$ versus $\ln C_{e}$ enables the determination of the isotherm constants $B_{1}$ and $K_{t}$ from the slope and the intercept, respectively. $K_{t}$ is the equilibrium binding constant $(1 / \mathrm{mol})$ corresponding to the maximum binding energy and constant $B_{1}$ is related to the heat of adsorption.

The Tempkin isotherm plots for CSC and CAC are shown in Figure 13.

From Figure 13, slope $=B_{1}=31.389$ and intercept $=75$.

Now,

$$
q_{e}=B_{1} \ln K_{t}+B_{1} \ln C_{e} .
$$

For CSC, $B_{1}=31.389$ and $K_{t}=10.90$.

From Figure 13, slope $=57.93$ and intercept $=90$.

For CAC, $B_{1}=119.94$ and $K_{t}=4.72$.

3.4. Adsorption Kinetics. The rate of adsorption of organic matter on to CSC and CAC was studied and the rate constant 


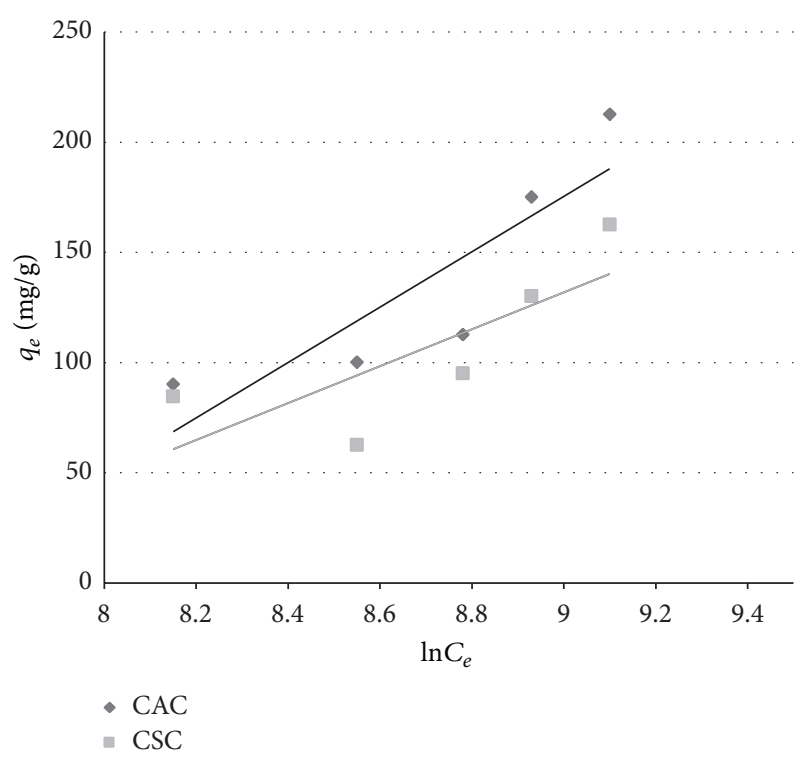

FIGURE 13: Tempkin adsorption isotherm $C_{o}=13120 \mathrm{mg} / \mathrm{L}$.

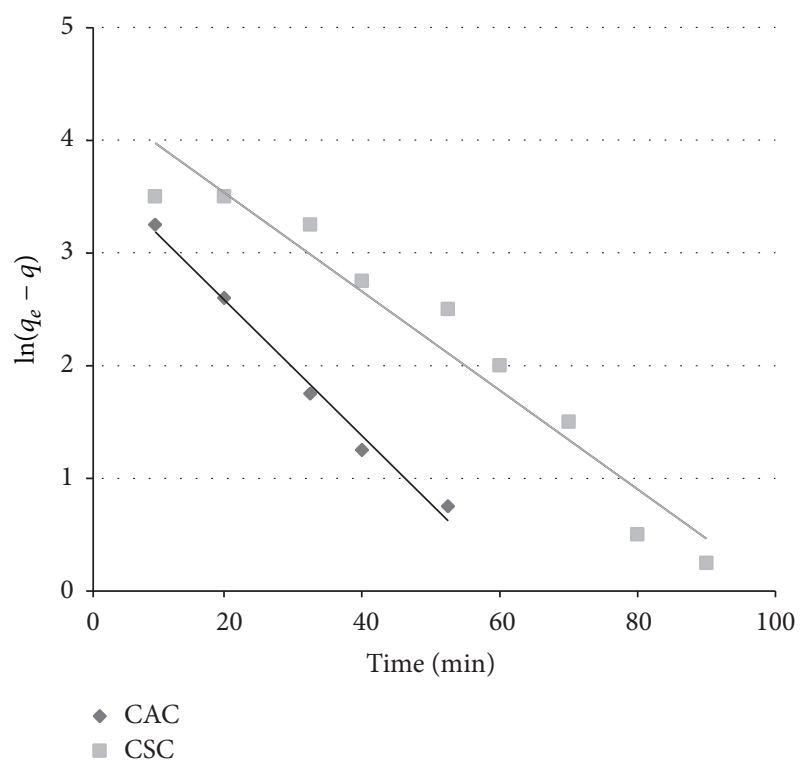

Figure 14: Lagergren plot $C_{o}=13120 \mathrm{mg} / \mathrm{L}$, adsorbent dose $=2 \mathrm{gms}$, $\mathrm{Temp}=30^{\circ} \mathrm{C}$.

$K_{\text {ad }}$ of the process for organic matter was determined using Lagergren rate equation. Figure 14 represents the Lagergren plot for the above system:

$$
\ln \left(q_{e}-1\right)=\ln q_{e}-\left(\frac{K_{\mathrm{ad}}}{2.303}\right) t
$$

where $q=$ amount adsorbed at time " $t$ ", $K_{\mathrm{ad}}=$ adsorption constant, and $q_{e}=$ equilibrium uptake.

At equilibrium, COD removal is Nil. So, $q_{e}=0$ :

$$
\ln \left(q_{e}-q\right)=\ln q_{e}-\left(\frac{K_{\mathrm{ad}}}{2.303}\right) t
$$

For CSC, from Figure 14, slope is $\left[K_{\mathrm{ad}} / 2.303\right]=5.111-$ $3.084 / 20-70=-0.04054$ :

$$
K_{\mathrm{adcsc}}=0.09336 \mathrm{~min}^{-1} .
$$

For CSC, from Figure 14, slope is $\left[K_{\mathrm{ad}} / 2.303\right]=4.892-$ $2.324 / 10-50=-0.0642$ :

$$
K_{\text {adcac }}=0.1478 \mathrm{~min}^{-1} \text {. }
$$

The linear plots of $\ln \left(q_{e}-q\right)$ versus $t$ for COD removal shown in Figure 14, indicate the applicability of Lagergren first order equation.

3.5. Cost Analysis. One of the most challenging elements in a design will be estimating the cost to build and operate the wastewater treatment facility that is designed. Cost estimation is also an important element when selecting between alternative designs [24].

For treating 1 liter of distillery spent wash, using CAC as adsorbent, time required $=22.22$ minutes, amount of CAC required $=32$ gms, cost of adsorbent $\mathrm{CAC}=\mathrm{Rs} .300$ per $\mathrm{kg}$, and cost of adsorbent CAC required to treat 1 liter of distillery spent wash $=$ Rs. 9.60.

For treating 1 liter of distillery spent wash, using CSC as adsorbent, time required $=22.22$ minutes, amount of CSC required $=36$ gms, and cost of adsorbent CSC $=$ Rs. 100 per $\mathrm{kg}$.

Cost of adsorbent CSC required to treat 1 liter of distillery spent wash $=$ Rs. 3.60. On comparing the cost of treatment of distillery spent wash using both CSC and CAC, it can be observed that treatment using CSC as adsorbent is much cheaper than that using CAC as adsorbent.

However, as far as the production of sugar is concerned, $0.4-0.45$ tone of molasses is produced per ton of sugar. About $90 \%$ of the total molasses produced is utilized for production of alcohol. For producing 1 liter of alcohol about 10-15 liters of spent wash is produced. Hence for producing 1 liter of alcohol, treatment cost of spent wash is about Rs. 96 by using commercial activated carbon as adsorbent and Rs.36/- by using coconut shell as adsorbent. Thus it can be observed that for treating 1 liter of distillery spent wash, there is a difference of Rs. 6 between the treatments by two adsorbents \{CSC and $\mathrm{CAC}$.

\section{Conclusions}

Coconut shell activated carbon was synthesized and characterized for comparison of adsorption capacities with commercial activated carbon. The results revealed that CAC gives the best result between the two adsorbents, that is, coconut shell carbon $\{\mathrm{CSC}\}$ and commercial activated carbon $\{\mathrm{CAC}\}$ tested for COD reduction from distillery spent wash. However, CSC also showed quiet effective adsorbent capacities. Though the adsorption capacity of CSC is lower than that of commercial grade activated carbon, the low material cost makes it an attractive option for the treatment of effluents. The treatment of distillery spent with CSC becomes highly effective, as it is a readily and locally available low cost absorbent which needs not be regenerated. 
With the increase in adsorbent dosage there is an increase in percentage COD removal from the distillery spent wash. Change in natural $\mathrm{pH}$ of the distillery spent wash caused color removal due to the structural changes being affected in the adsorbent molecules. COD removal by both adsorbents, that is, CAC and CSC, is the maximum at a pH between 3 and 5. Effect of initial concentration on COD removal by both CSC and CAC shows that the percentage COD removal increases with increase in initial concentration (above $8580 \mathrm{mg} / \mathrm{lit}$ ) for initial contact time intervals and decreases with increase in initial concentration as the saturation of adsorbent is reached. Adsorption capacity decreases with increase in temperature for both the adsorbents. Breakthrough time increases with increase in bed height and decrease in flow rate for the column adsorption. By operating CSC column in series with CAC column the efficiency of carbon utilization is increased.

The equilibrium time was nearly one hour for both CAC and CSC adsorbents. The correlation for equilibrium adsorption data were well fitted by the Langmuir and Tempkin adsorption isotherm for both the adsorbents. Bohart Adam's equation was found to be applicable for the column study. The adsorption kinetics was well in agreement with the Lagergren plots revealing first order rate.

From the results obtained it can be stated that though CAC is more efficient adsorbent than CSC, but due to high cost and 15 to $20 \%$ loss of CAC during regeneration CSC is more preferable than CAC for COD removal from sugardistillery spent wash. However, for evaluation of the technical and economical feasibility, more research is required on pilot plant scale, so that this low cost adsorbent can be used on larger commercial scale for removal of COD from distillery spent wash.

\section{Future Insights}

Expansion of this technology to large-scale applications should be encouraged. As used coconut shells find their way as urban and rural refuse; exploitation of this waste for waste water treatment will dispose this waste in a safer manner.

Besides the gold mining industries, the breweries, and soft drink industries that currently use activated carbon, other potential users such as the textile industries, soap manufacturing industries, vegetable oil nulls, and the Water and Sewerage Corporation can also be sensitied to use this commodity, thereby creating more market for the product. The pilot studies to develop a national capability for the production of activated carbon form coconut shells will, among several benefits, contribute to measures for abating the environmental degradation caused by dumping of agricultural wastes. Improved public education to ensure awareness of the technology and its benefits, both environmental and economic, is recommended.

More experimental work on removal of organic matter from other industrial effluents by using coconut shell ash as adsorbent should be encouraged in order to prove the suitability of this low cost adsorbent for waste water treatment.

Adsorption column studies should be carried out for different column configurations to get the characteristic dependence of the adsorption capacity and other parameters.
Design parameters for scaled up adsorption column should thereafter be fixed for the removal of COD from distillery spent wash. Costing of the adsorption based on industrial scale treatment system should be carried out to popularize the adsorption technique. Computing, modeling, and simulation will be carried out for the large-scale plants based on the computations proposed.

\section{Conflict of Interests}

The authors declare that there is no conflict of interests regarding the publication of this paper.

\section{References}

[1] B. Subba Rao, Aerobic Composting of Spent Wash, Environmental Protection Research Foundation, Sangli, India, 2008.

[2] A. G. Patil, V. V. Deshpande, and P. L. Kulkarni, Distillery Spent Wash: A Source for Production of Chemicals, Deccan Sugar Institute, Pune, India, 2009.

[3] B. S. Rao, S. V. Ranade, and J. M. Gadgil, "Wealth from waste," in Proceedings of the 3rd International Conference on Appropriate Waste Management Technologies for Developing Countries, pp. 25-26, NEERI, Nagpur, India, 1995.

[4] L. M. Arulanantham, T. V. Ramkrishna, and S. N. Bal, "Studies on fluoride removal by Coconut shell carbon," Indian Journal of Environmental Protection, vol. 12, no. 7, 1992.

[5] G. N. Pandey and G. S. Carney, Environmental Engg, TATA McGraw-Hill, New York, NY, USA, 2010.

[6] I. A. Rahman, Y. Y. Singh, M. F. Bari, and B. Saad, "Adsorption of paraquat by treated and untreated rice husks studied by flow injection-analysis," Research Journal of Chemistry and Environment, vol. 9, no. 1, pp. 17-22, 2005.

[7] R. Shyamala, S. Sivakamasundari, and P. Lalitha, "Comparison of the adsorption potential of biosorbents-waste tealeaves and rice husk, in the removal of chromium (VI) from waste water," Journal of Industrial Pollution Control, vol. 21, no. 1, pp. 31-36, 2005.

[8] S. D. Foust and O. M. Aly, "Adsorption process for water treatment," Science Report, 1986.

[9] M. K. B. Gratuito, T. Panyathanmaporn, R.-A. Chumnanklang, N. Sirinuntawittaya, and A. Dutta, "Production of activated carbon from coconut shell: optimization using response surface methodology," Bioresource Technology, vol. 99, no. 11, pp. 48874895, 2008.

[10] S. D. Khattri and M. K. Singh, "Adsorption of basic dyes from aqueous solution by natural adsorbent," Indian Journal of Chemical Technology, vol. 6, no. 2, pp. 112-116, 1999.

[11] A. S. Dadhich, S. K. Beebi, and G. V. Kavitha, "Adsorption of $\mathrm{Ni}$ (II) using agrowaste, rice husk," Journal of Environmental Science and Engineering, vol. 46, no. 3, pp. 179-185, 2004.

[12] R. J. Krupadam and A. V. S. Prabhakar Rao, "Removal of lead from industrial effluents using coconut shell carbon," Environmental Pollution Control Journal, vol. 56, no. 2, pp. 5253, 1997.

[13] S. A. Raj, "Adsorption behaviour of nickel on activated carbon," Indian Journal of Environmental Protection, vol. 24, no. 7, pp. 530-533, 2004.

[14] K. Vasanth Kumar and K. Subanandam, "Studies on decolorisation of basic dye onto carbonized agro based waste adsorbent," Environmental Pollution Control Journal, vol. 5, no. 2, p. 8, 2002. 
[15] K. V. Kumar, "Studies on adsorption of basic dyes on to agro-based wastes-part I: kinetic studies," Indian Journal of Environmental Protection, vol. 22, no. 11, pp. 1236-1240, 2002.

[16] K. Palanivelu and N. Elangovan, "Phosphate removal studies using $\mathrm{Al}$ impregnated coconut shell carbon," Indian Journal of Environmental Protection, vol. 16, no. 3, pp. 183-185, 1996.

[17] S. T. M. L. D. Senevirathna, S. Tanaka, S. Fujii et al., "Adsorption of perfluorooctane sulfonate (n-PFOS) onto non ion-exchange polymers and granular activated carbon: batch and column test," Desalination, vol. 260, no. 1-3, pp. 29-33, 2010.

[18] S. Sohail Ayub, S. Iqbal Ali, N. A. Khan, and H. S. Danish, "Treatment of waste water by agricultural waste-a review," Environmental Pollution Control Report, 1998.

[19] S. Rengaraj, B. Arabindoo, and V. Murugesan, "Preparation and characterisation of activated carbon from agricultural wastes," Indian Journal of Chemical Technology, vol. 6, no. 1, pp. 1-4, 1999.

[20] S. Dahiya and A. Kaur, "Studies on fluoride removal by coconut coir pith carbon," Indian Journal of Environmental Protection, vol. 19, no. 11, pp. 811-814, 1999.

[21] D.S. Ramteke, S.R. Wate, and C.A. Moghe, "Comparative adsorption studies of distillery waste on ativated carbon," Indian Journal of Environmental Health, vol. 31, no. 1, pp. 17-24, 1989.

[22] S. Satyanarayan, A. Juwarkar, and S. N. Kaul, "Distillery Waste Water Treatment-A case Study," NEERI, Nagpur-20, 2009.

[23] S. Gupta and R. P. Singh, "Comparative adsorption study of toxic metal by waste product," Indian Journal of Environmental Protection, vol. 24, no. 11, pp. 863-866, 2004.

[24] G. G. Stavropoulos and A. A. Zabaniotou, "Minimizing activated carbons production cost," Fuel Processing Technology, vol. 90, no. 7-8, pp. 952-957, 2009. 

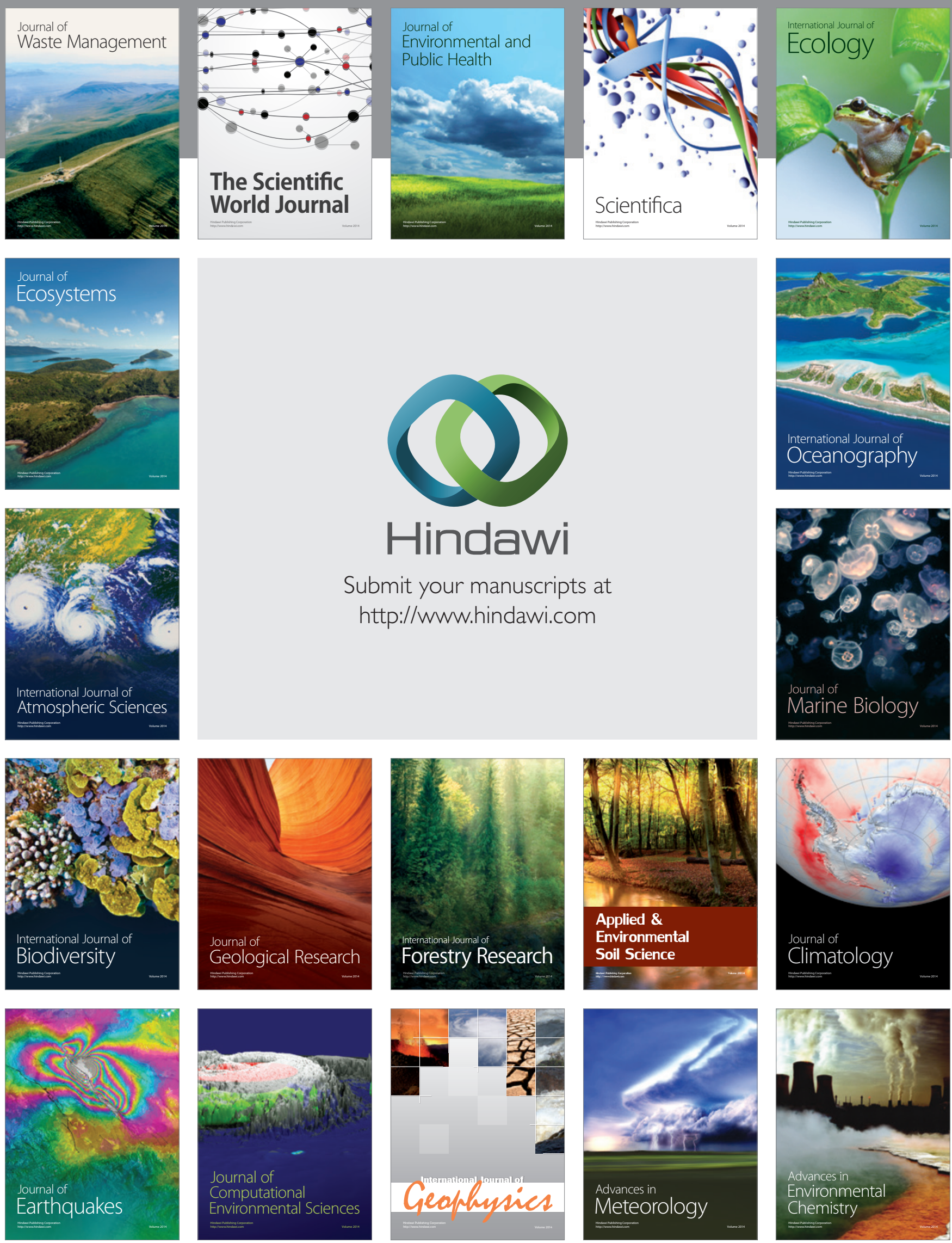